\title{
Modeling and Correlating Rut Depth Observed in Different Asphalt Mixture Performance Tests
}

\author{
SABAHAT HUSSAN*, MUMTAZ AHMED KAMAL*, AND IMRAN HAFEEZ* \\ RECEIVED ON 12.05.2017 ACCEPTED ON 21.08.2017
}

\begin{abstract}
The purpose of research is to model and correlate the laboratory rutting behavior of indigenous asphalt mixtures, prior to placing in the field. Extensive laboratory testing was carried out on thirty representative wearing course mixtures using two types of rutting performance tests i.e. CWTT (Cooper Wheel Tracking Tests), and APA(Asphalt Pavement Analyzer) tests. The mixture ranking is consistent for both laboratory performance tests at the tested temperature conditions of $40 \mathrm{and} 50^{\circ} \mathrm{C}$. Laboratory rutting prediction models have been developed by non-linear regression analysis technique. Significant independent variables involved in the model are temperature, number of passes in case of CWTT or number of cycles in case of APA tests, bitumen penetration value, and Flakiness index of coarse aggregates fraction. A strong relationship has been observed between measured and predicted values of rut depth in terms of $R^{2}$ value of 0.92 and 0.95 for CWTT and APA tests, respectively. A reasonable empirical quadratic function correlation $\left(\mathrm{R}^{2}=0.69\right)$ has been developed between rut depth of CWTT and rut depth in APA test.
\end{abstract}

Key Words: Rutting, Asphalt Mixture, Performance Tests, Prediction Models.

\section{INTRODUCTION}

$\mathrm{R}$ utting is defined as flexible pavement distress indicated by continuous depression parallel to traffic direction along the wheel paths. It has been commonly observed at locations where heavy traffic travels at slow speed, such as intersections, bus bays, turning lanes etc.

Rutting distress has been primarily considered as load induced distress. Materials of surface, base, subbase and subgrade layers should be capable to resist this load induced distress. Hence, careful selection of materials along with adopting proper design and quality control procedures is mandatory requirement for a rutting resistant pavement. Rutting in flexible asphaltic pavements is generally attributable to various factors such as asphalt mixture properties, which further include aggregate gradation, types of aggregates, binder type and its properties and extent of applied compaction efforts. Factors related to loading pattern include types of vehicles, tire material, tire pressure, speed of vehicles and axle load. Similarly, environmental factors, such as climatic conditions of the area and pavement temperature also affect the type and extent of rutting[1].

Authors E-Mail: (sabahathussan@yahoo.com,drmakamal@yahoo.com, imranhafeez783@yahoo.com)

* Department of Civil Engineering, University of Engineering \& Technology, Taxila.

This is an open access article published by Mehran University Research Journal of Engineering and Technology, Jamshoro under the CC by 4.0 International License. 
Various laboratory wheel tracking devices has been used to simulate rutting propensity of different asphalt mixtures in the past. HWTT (Hamburg Wheel Tracking Test) could be efficiently used to evaluate laboratory rutting resistance of recycled asphalt mixtures [2]. Doyle and Howard reported that PURWheel (Purdue University Wheel Tracker)dry and APAwere observed to be equally good indicators of rutting potential [3]. Several researchers used wheel tracking test to study the effect of modifiers in asphalt mixtures [4,5]. The APA was validated as a useful APT (Accelerated Pavement Testing) tool. Researchers used APA as an effective tool to rank asphalt mixtures in terms of their laboratory rutting performance [6-9].CWT (Cooper Wheel Tracker) was effectively used to judge the erodability of cement treated pavement layers along with rutting prediction [10]. It had also been observed that general ranking of asphalt mixtures with respect to rut depth by CWT and rutting factor $\left(E^{*} / \sin \varphi\right)$ by dynamic modulus test was similar [11].

A rutting prediction model is an equation that is used to predict pavement life in terms of a number of repetitions (or loading cycles) to failure. Apeagyei developed multiple regression model to describe the relationship among FN (Flow Number), dynamic modulus, and gradation as shown in Equation (1).

$F N=\beta_{o}=\sum_{i=1}^{10} \beta_{i} x_{i}$

Where $\mathrm{x}_{1}$ is percent air voids, $\mathrm{x}_{2}$ is percent passing $19 \mathrm{~mm}$ sieve, $\mathrm{x}_{3}$ is percent passing $12.5 \mathrm{~mm}$ sieve, $\mathrm{x}_{4}$ is percent passing $9.5 \mathrm{~mm}$ sieve, $\mathrm{x}_{5}$ is percent passing $4.75 \mathrm{~mm}, \mathrm{x}_{6}$ is percent passing $2.36 \mathrm{~mm}$ sieve, $\mathrm{x}_{7}$ is dynamic modulus at $38^{\circ} \mathrm{C}$ and $10 \mathrm{~Hz}, \mathrm{x}_{8}$ is dynamic modulus at $38^{\circ} \mathrm{C}$ and $1 \mathrm{~Hz}, \mathrm{x}_{9}$ is dynamic modulus at $38^{\circ} \mathrm{C}$ and $0.1 \mathrm{~Hz}, \mathrm{x}_{10}$ is voids in mineral aggregates and $\beta_{\mathrm{i}}$ are respective regression parameters [12]. The prediction model between laboratory rut depth and the dynamic stability of each asphaltic layer, and the longitudinal grade was developed using multiple nonlinear regression analysis as shown in Equation (2).

$\mathrm{RD}=\mathrm{k}_{1}+\mathrm{k}_{2} \ln \mathrm{DS}_{\mathrm{S}}+\mathrm{k}_{3} \mathrm{DS}_{\mathrm{I}}+\mathrm{k}_{4} \ln \mathrm{DS}_{\mathrm{B}}+\mathrm{K}_{5} \mathrm{i}$

Where $\mathrm{RD}$ is rut depth, $\mathrm{DS}_{\mathrm{S}}, \mathrm{DS}_{\mathrm{I}}, \mathrm{DS}_{\mathrm{B}}$ is dynamic stability of surface, intermediate and base layer, respectively; $i$ is gradient in percent, while $\mathrm{k}_{1}$ through $\mathrm{k}_{5}$ are respective regression coefficients [13]. Ahmed and Erlingsson carried out two diûerent types of tests: an ELWT (Extra Large Wheel Tracking) test and a full-scale accelerated pavement test using a HVS (Heavy Vehicle Simulator) to compute model parameters for MEPDG (Mechanistic Empirical Pavement Design Guide) model [14]. Tapkin et. al. [15] presented an application of ANN (Artificial Neural Networking) technique to predict permanent strain of polypropylene modified asphalt mixtures in a repeated load axial test. An ANN based rutting propensity model was developed for asphalt mixtures; percentages of coarse aggregate, filler, bitumen, air voids, voids in mineral aggregate, and Marshall Quotient were employed as the predictor variables using flow number test [16]. Archilla and Madanat [17] developed a non-linear rutting regression model based on observations of AASHO (American Association of State Highway and Transportation Officials) Road test between numbers of ESALs along with thawing index as an environmental parameter. Rutting was modeled as a function of traffic, temperature, and mix characteristics, including voids filled with asphalt, asphalt content, in-place air voids, surface area, and the densification slope by Archilla [18]. A novel ME (Mechanistic Empirical) rutting model developed for hot-mixed asphalt HMA overlay thickness design and analysis as shown in Equation (3).

$$
R D==\sum_{l=1}^{n} k D^{\int\left(U_{i}^{+}-U_{i}^{-}\right) \mu_{i} N^{-\alpha_{i}}}
$$

Where $\mathrm{R}_{\mathrm{D}}$ is rut depth, $\mathrm{k}_{\mathrm{RD}}$ is calibration factor, $\mathrm{U}_{\mathrm{i}}^{+}$and $\mathrm{U}^{-}$ ${ }_{i}$ are vertical deflections at top and bottom of finite layer i, 
$\mathrm{N}$ is number of cycles, and $\alpha_{i}$ and $\mu_{i}=$ permanent deformation parameters of overlay layer i [19]. A research explained the development of a model for estimating the rutting performance of dense graded asphalt concrete pavement under various temperatures and loadsas shown in Equation (4).

$\mathrm{R}_{\mathrm{D}}=10^{\alpha} \mathrm{N}^{\beta} \mathrm{T}^{\gamma}$

Where $R_{D}$ is rut depth, $T$ is temperature, $N$ is number of ESALS, and $\alpha, \beta, \gamma$ are regression parameters [20].

Statistical analyses performed by Rushing and Little indicated that the rate of increase in permanent strain $(\mathrm{m})$ and the FT (Flow Time) value determined from triaxial static creep testing provides the strongest correlation to APA rutting (i.e. $\mathrm{R}^{2}=0.54$ and 0.34 ), as compared to correlation of APA rutting with FN value (i.e. $\mathrm{R}^{2}=0.28$ ) obtained from repeated load test [21]. Chen et. al. [22] concluded that a strong correlation exists between the FLWT (French Loaded Wheel Tracker), DS (Dynamic Stability) and APA rut depth for the mixtures studied.

Literature review suggests that various wheel tracking devices including CWTT and APA has been effectively used as laboratory rutting performance tests. Various rutting prediction models have been developed in the past using laboratory rutting performance data of different virgin and modified asphalt mixtures. This research study focuses on development of rutting prediction model with novel combination of variables. The variables included in the model have been selected on basis of their significance on rutting propensity of asphalt mixtures. As CWTT has been designed in accordance with European standard of EN 12697-22 and APA according to American standard of AASHTOTP 63-03; the empirical correlation between results of both tests could be helpful in introducing a combined rutting quality assessment protocol [23,24]. Therefore, a suitable correlation has been established between the results of two commonly used wheel tracking devices i.e. CWTT and APA test.

\section{OBJECTIVES}

The main objectives of the study were:

- $\quad$ To evaluate rutting performance of selected asphalt mixtures under local conditions using standard test procedures.

- $\quad$ To develop laboratory rutting prediction models for the selected asphalt mixtures using the performance tests of CWTT and APA.

- $\quad$ To compare and correlate rutting performance of CWTT and APA rutting tests.

\section{RESEARCH METHODOLOGY}

The methodology used to achieve the research objectives has been summarized in Fig. 1. The representative combinations of the constituent materials are selected for the mixtures of wearing course and base course layers. After determining the optimum binder content of these mixtures using Marshall method, rutting performance was evaluated by two rutting performance tests. Based on the results of these tests, rutting prediction models are developed using nonlinear regression technique with SPSS statistical analysis software. Rutting results were compared and a correlation was established between rut depth of CWTT and rut depth observed in APA.

As can be seen from Fig. 1, the methodology was planned in four steps i.e. selection of materials and their characterization, selection of representative mixtures and their design, rutting performance evaluation and ranking of asphalt mixtures, and development of rutting prediction models and correlation between rut depth of two different simulative wheel tracking devices. 


\section{MATERIALS AND METHODS}

\subsection{Aggregates}

Three aggregate sources of limestone origin, namely Ubhan Shah Quarry in Sindh Province, Sargodha and
Margallah Quarry in Punjab province have been selected in this study. Ubhan Shah aggregate quarry represents the southern part of country while Margallah and Sargodha quarry represents the northern part. Results of the physical and mechanical tests carried out on aggregates have been summarized in Table 1 .

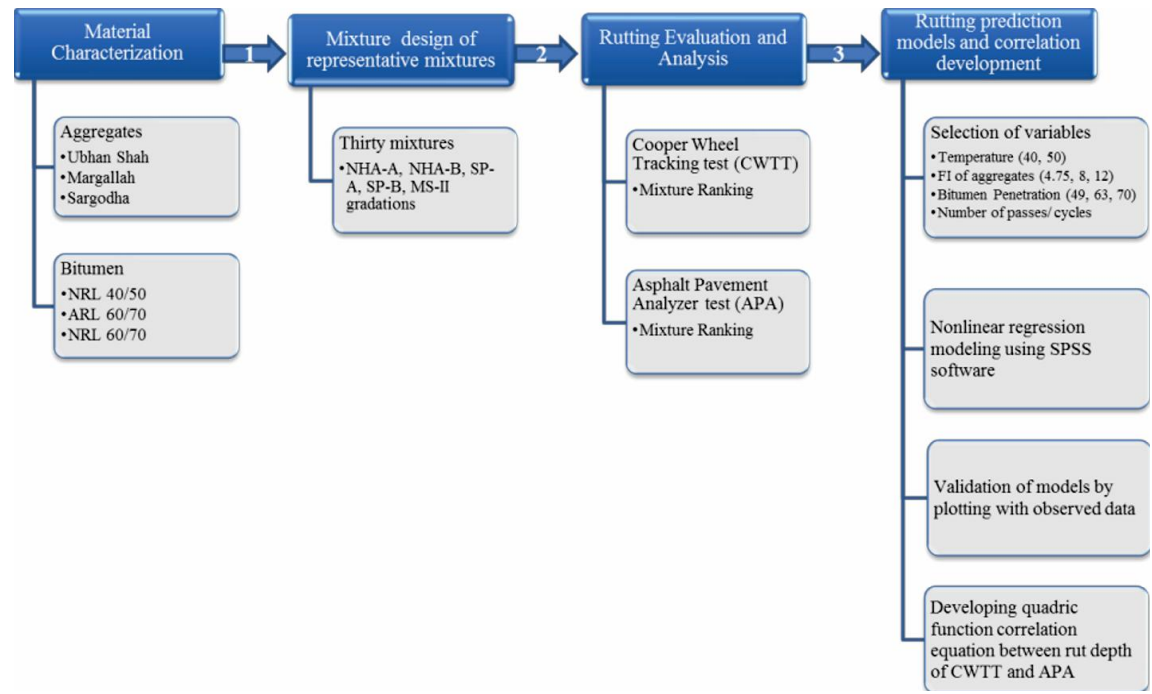

FIG. 1. FLOWCHART FOR EXPERIMENTAL PROGRAM

TABLE 1. QUALITATIVE TESTS OF AGGREGATES

\begin{tabular}{|c|c|c|c|c|c|c|c|c|c|c|c|c|}
\hline Standarc & est Method & $\begin{array}{c}\text { ASTM } \\
\text { C131 }\end{array}$ & $\begin{array}{c}\text { ASTM } \\
\text { C88 }\end{array}$ & $\begin{array}{c}\text { ASTM } \\
\text { C142 }\end{array}$ & $\begin{array}{l}\text { ASTM } \\
\text { D4791 }\end{array}$ & $\begin{array}{l}\text { ASTM } \\
\text { D5821 }\end{array}$ & \multicolumn{2}{|c|}{ ASTM D4791 } & $\begin{array}{l}\text { ASTM } \\
\text { D4318 }\end{array}$ & $\begin{array}{l}\text { ASTM } \\
\text { D2419 }\end{array}$ & \multicolumn{2}{|c|}{ ASTM C1252 } \\
\hline No. & $\begin{array}{l}\text { Aggregate } \\
\text { Source }\end{array}$ & $\begin{array}{c}\text { Los } \\
\text { Angeles } \\
\text { Abrasion } \\
\text { Value } \\
(\%) \\
\end{array}$ & $\begin{array}{c}\text { Soundness } \\
(\%)\end{array}$ & $\begin{array}{l}\text { Clay } \\
\text { Lumps } \\
(\%)\end{array}$ & $\begin{array}{c}\text { Elongation } \\
(\%)\end{array}$ & $\begin{array}{c}\text { Fractured } \\
\text { Faces } \\
(\%)\end{array}$ & \multicolumn{2}{|c|}{ Flakiness (\%) } & $\begin{array}{l}\text { Plasticity } \\
\text { Index }\end{array}$ & $\begin{array}{c}\text { Sand } \\
\text { Equivalent } \\
(\%)\end{array}$ & \multicolumn{2}{|c|}{ Void Content (\%) } \\
\hline \multirow{4}{*}{1.} & \multirow{4}{*}{$\begin{array}{c}\text { Ubhan } \\
\text { Shah }\end{array}$} & \multirow{4}{*}{21} & Coarse & \multirow{4}{*}{0.94} & \multirow{4}{*}{16.5} & \multirow{12}{*}{$\begin{array}{c}100 \% \\
\text { Crushed } \\
\text { Aggregate }\end{array}$} & \multirow{4}{*}{\multicolumn{2}{|c|}{12.05}} & \multirow{4}{*}{\multicolumn{2}{|c|}{8.25}} & \multicolumn{2}{|c|}{ Coarse } \\
\hline & & & 0.18 & & & & & & & & \multicolumn{2}{|c|}{-} \\
\hline & & & Fine & & & & & & & & \multicolumn{2}{|c|}{ Fine } \\
\hline & & & 2.48 & & & & & & & & \multicolumn{2}{|c|}{41} \\
\hline \multirow{4}{*}{2.} & \multirow{4}{*}{ Margallah } & \multirow{4}{*}{23.3} & Coarse & \multirow{4}{*}{0.84} & \multirow{4}{*}{2.2} & & \multirow{4}{*}{\multicolumn{2}{|c|}{4.75}} & \multirow{8}{*}{ Non-Plastic } & \multirow{4}{*}{75} & \multicolumn{2}{|c|}{ Coarse } \\
\hline & & & 7.1 & & & & & & & & \multicolumn{2}{|c|}{48.7} \\
\hline & & & Fine & & & & & & & & \multicolumn{2}{|c|}{ Fine } \\
\hline & & & 4.7 & & & & & & & & \multicolumn{2}{|c|}{37} \\
\hline \multirow{4}{*}{3.} & \multirow{4}{*}{ Sargodha } & \multirow{4}{*}{22} & Coarse & \multirow{4}{*}{0.88} & \multirow{4}{*}{2} & & \multirow{4}{*}{\multicolumn{2}{|c|}{6}} & & \multirow{4}{*}{70} & $\overline{\mathrm{Co}}$ & \\
\hline & & & 4.3 & & & & & & & & & \\
\hline & & & Fine & & & & & & & & & \\
\hline & & & 3.6 & & & & & & & & 4 & \\
\hline $\begin{array}{l}\mathrm{Spe} \\
\mathrm{Rec}\end{array}$ & $\begin{array}{l}\text { ication } \\
\text { ements }\end{array}$ & $\begin{array}{c}40 \% \\
\text { Maximum }\end{array}$ & $\begin{array}{c}12 \% \\
\text { Maximum }\end{array}$ & $\begin{array}{c}1 \% \\
\text { Maximum }\end{array}$ & $\begin{array}{c}\text { Base } \\
\text { Course }=1- \\
5 \% \\
\text { Wearing } \\
\text { Course }=1- \\
0 \%\end{array}$ & $\begin{array}{c}90 \% \\
\text { Minimum }\end{array}$ & $\begin{array}{l}\text { Base } \\
\text { Course } \\
=15 \%\end{array}$ & $\begin{array}{c}\text { Wearing } \\
\text { Course } \\
=10 \%\end{array}$ & $\begin{array}{c}\text { LL } 25 \\
\text { Max PI } 6 \\
\text { Max }\end{array}$ & $\begin{array}{c}45 \% \\
\text { Minimum }\end{array}$ & $\begin{array}{c}\text { Coarse } \\
\text { Aggregate } \\
=50 \% \\
\text { (maximum) }\end{array}$ & $\begin{array}{c}\text { Fine } \\
\text { Aggregate } \\
=45 \% \\
\text { (maximum) }\end{array}$ \\
\hline
\end{tabular}

Mehran University Research Journal of Engineering \& Technology, Volume 37, No. 3, July, 2018 [p-ISSN: 0254-7821, e-ISSN: 2413-7219] 
The five centerline gradations selected for the study has been shown in Fig 2. The centerline gradation curves shown in Fig. 2 follow average of upper and lower limiting values of gradation envelope. The relative coarse fraction, designated by material passing \#4 $(4.75 \mathrm{~mm})$ sieve, has been used to define the relative fineness of a specific gradation. Fig. 2 indicates that among the selected wearing course gradations; NHA-A is coarser, followed by SP-B, NHA-B, MS-II and SP-A gradations, respectively. NHA$A$ and NHA-B designates coarse and fine gradation specified by NHA (National Highway Authority) Pakistan respectively; SP-A and SP-B designates Superpave specified fine and coarse gradation respectively; while MS-II designates fine gradation specified in Asphalt Institute Manual Series-II [25-27]. NMAS (Nominal Maximum Aggregate Size), defined as one sieve size larger than the first sieve on which more than $10 \%$ of the material retained, has values of 19.0, 19.0, 12.5, 12.5, and 12.5 for NHA-A, NHA-B, SP-B, SP-A and MS-II gradation respectively.

It has been inferred from Table 1 that the aggregates procured from Ubhan Shah Quarry are more flat and elongated as compared to that of Margallah and Sargodha Quarry. Sand equivalent value, Los Angeles Abrasion value, clay content, soundness and uncompacted voids of aggregate samples of all three sources are well within NHA specified limits [27].

\subsection{Bitumen}

Three different binders were selected from two sources i.e. NRL 40/50 and NRL 60/70 pen. grade from NRL (National Oil Refinery Karachi) and ARL 60/70 penetration grade from ARL (AttockOil Refinery). These bitumen sources have been primarily used for flexible pavements in Pakistan. Results of qualitative tests of selected binders have been tabulated in Table 2.

\subsection{Asphalt Mixture}

Marshall mixture design procedure had been adopted for the design of different asphalt mixtures. A standard hammer weighing $4.5 \mathrm{lbs}$ was dropped from height of 18 inches for 75 blows on either side of sample in Marshall Mold. A typical target value of $4 \%$ air voids had been used in the design procedure. The complete test matrix including mixture designation, OBC (Optimum Bitumen Contents) along with test and compaction conditions has been summarized in Table 2. Samples were prepared at $\mathrm{OBC}$ for two rutting performance tests of CWTT and APA test). Table 3 also shows the dimensions of the specimens for both rutting performance tests.

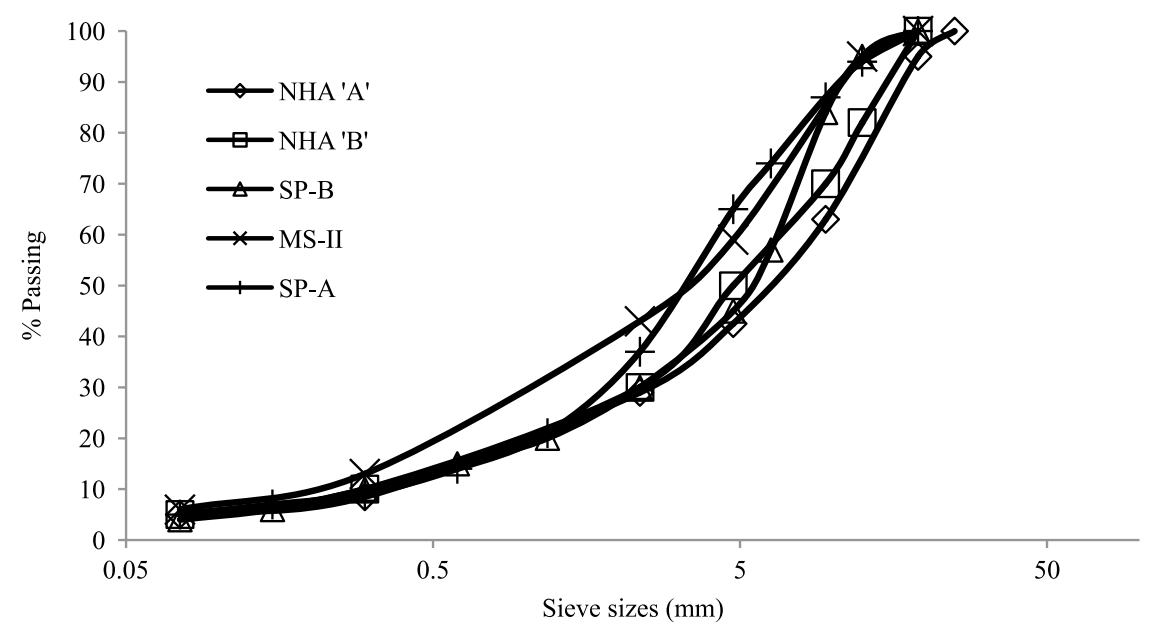

FIG. 2. CENTERLINE GRADATIONS CURVES OF ASPHALTIC WEARING COURSE

Mehran University Research Journal of Engineering \& Technology, Volume 37, No. 3, July, 2018 [p-ISSN: 0254-7821, e-ISSN: 2413-7219] 


\subsection{Sample Preparation}

Sieving of aggregates was performed using standard sieve sizes specified for each gradation. Aggregate batch was prepared by weighing aggregates retained on each sieve size. The aggregate material was placed in oven at a temperature of $110^{\circ} \mathrm{C}$ for 24 hours prior to mixing. Each sample was prepared at mixing temperature of $160 \pm 2^{\circ} \mathrm{C}$. Temperature during mixing was monitored by digital temperature gauge. After mixing, compaction was done by either Cooper roller compactor or SuperPave gyratory compactor, depending upon the required shape of

TABLE 2. QUALITATIVE TESTS OF BITUMEN

\begin{tabular}{|c|c|c|c|c|c|}
\hline \multicolumn{2}{|c|}{ Standard Test Method } & ASTM D5 & ASTM D36 & ASTM D113 & ASTM D92 \\
\hline No. & Bitumen Source & $\begin{array}{c}\text { Penetration } \\
\text { at } 25^{\circ} \mathrm{C} \\
(1 / 10 \text { th of } \mathrm{mm})\end{array}$ & $\begin{array}{c}\text { Softening } \\
\text { Point } \\
\left({ }^{\circ} \mathrm{C}\right)\end{array}$ & $\begin{array}{c}\text { Ductility } \\
(\mathrm{cm})\end{array}$ & Flash Point $\left({ }^{\circ} \mathrm{C}\right)$ \\
\hline 1. & NRL 60/70 & 70 & 46 & 100 & 291 \\
\hline 2. & NRL 40/50 & 49 & 49 & 100 & 296 \\
\hline 3. & ARL 60/70 & 63 & 48 & 100 & 262 \\
\hline
\end{tabular}

TABLE 3. TEST MATRIX FOR CWTT AND APA WITH SAMPLE PREPARATION PROTOCOLS

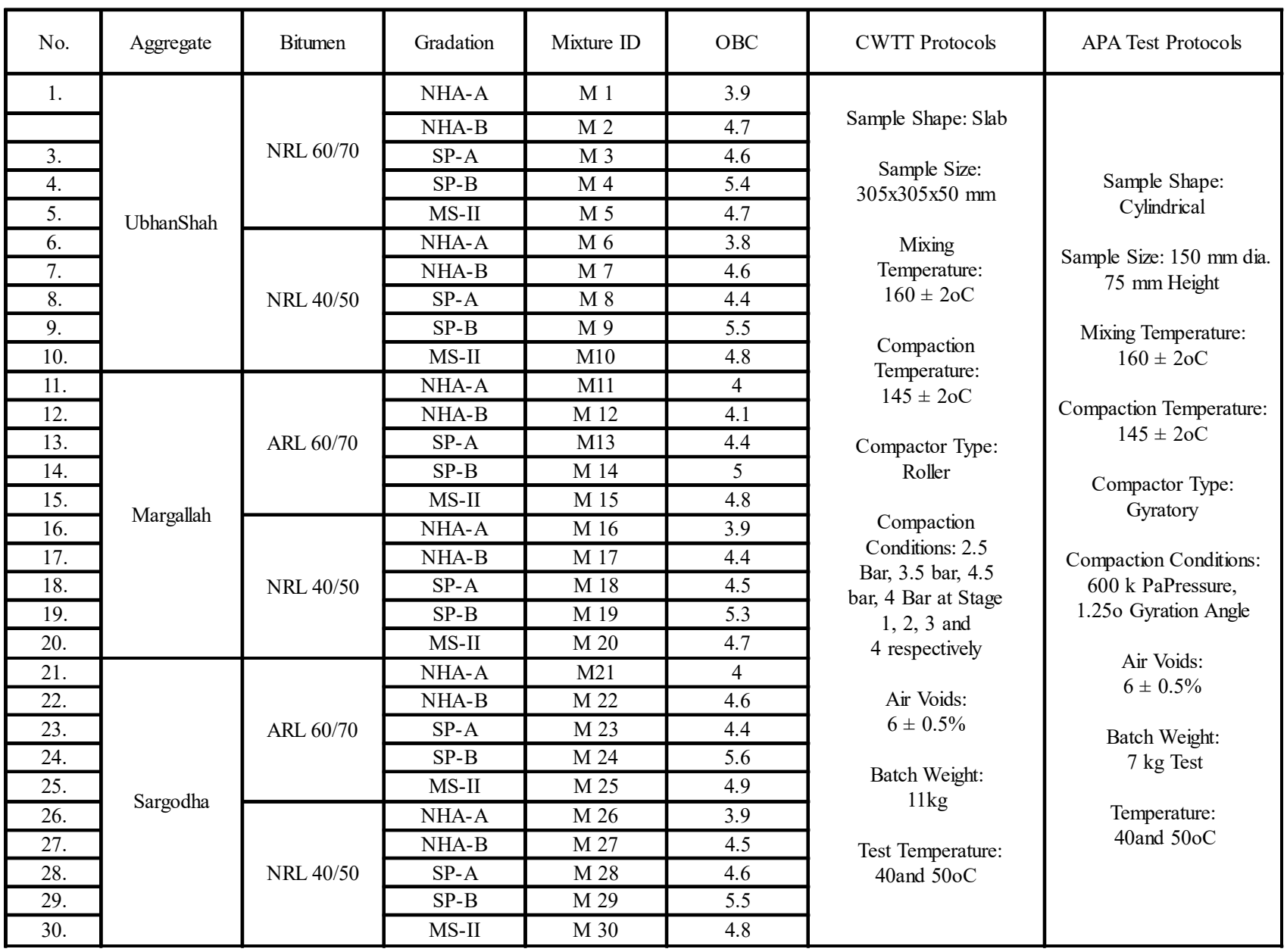

Mehran University Research Journal of Engineering \& Technology, Volume 37, No. 3, July, 2018 [p-ISSN: 0254-7821, e-ISSN: 2413-7219] 
specimens. The air voids were kept in range of $6 \pm 0.5 \%$. Three replicates for each test condition were prepared for both rutting performance tests. Cumulatively 360 samples were tested as a whole. The steps involved in sample preparation have been shown in Fig. 3.

\subsection{Sample Testing}

CWTT is used to assess the liability of an asphalt mixture to deform plastically at high temperatures under pressure

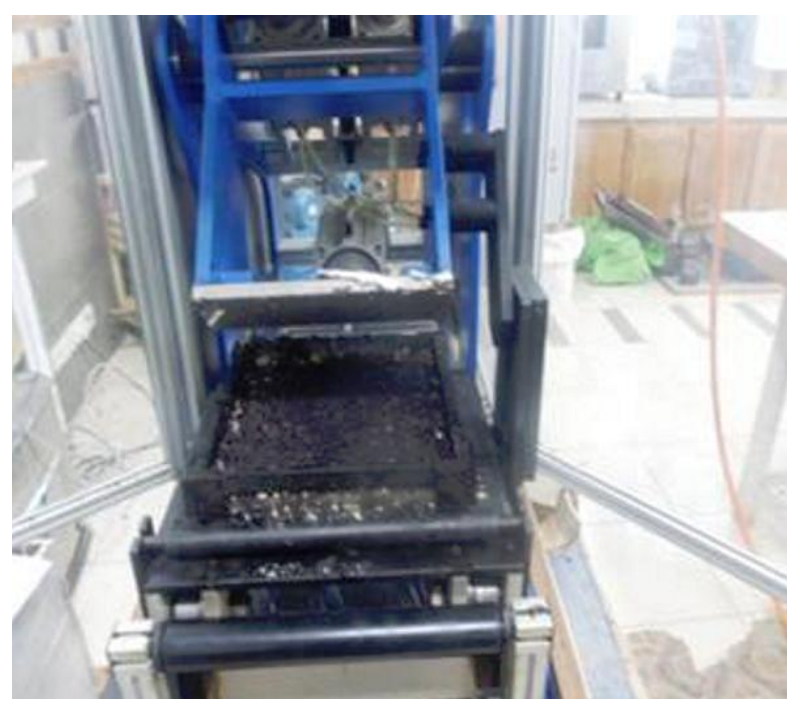

(a) COMPACTING SAMPLE BY ROLLER COMPACTOR

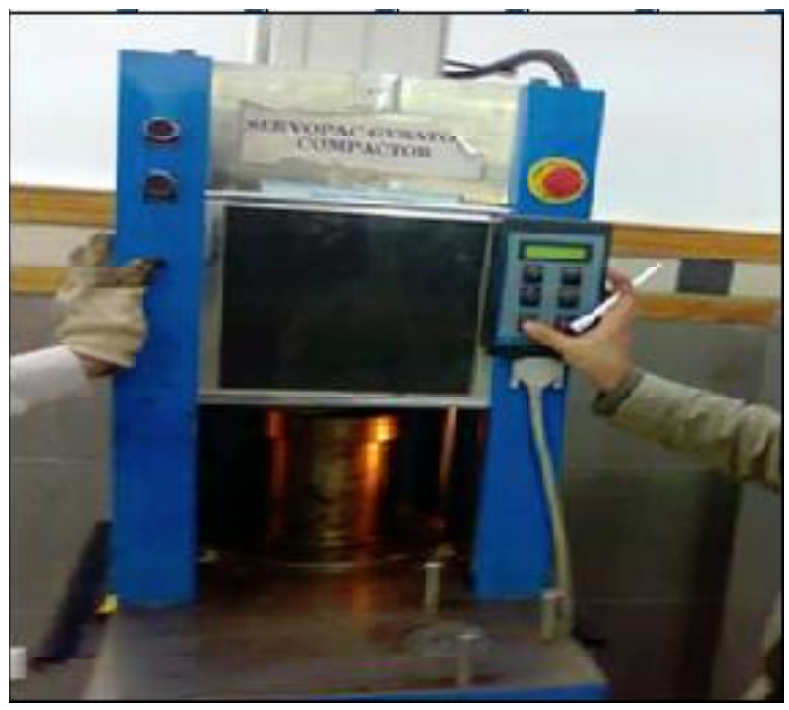

(c) COMPACTING SAMPLE BY GYRATORYCOMPACTOR caused by traffic. Cooper wheel tracking machine enables the test specimen in its cradle to move backwards and forwards under the loaded wheel. The center of the contact area of a solid rubber tire of $200 \mathrm{~mm}$ diameter and $50 \mathrm{~mm}$ thickness, undergoes simple harmonic motion with respect to the center of surface of the test specimen, with a total distance of travel $230 \pm 10 \mathrm{~mm}$ at a frequency of $26.5 \pm 1.0$ cycles per minute. The terminal number of passes is limited to 10,000 with loading magnitude of $700 \mathrm{~N}$. The

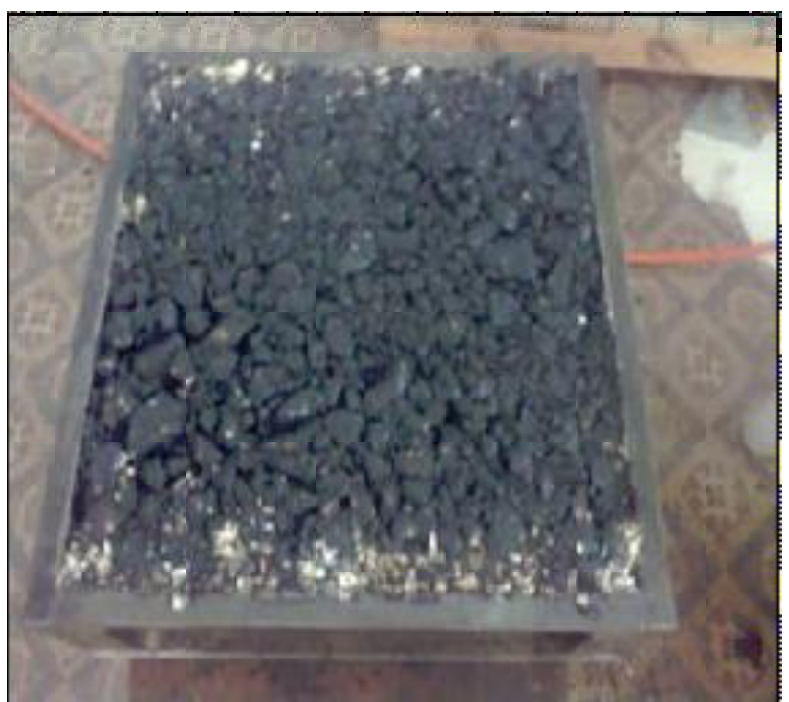

(b) CWTT SAMPLE

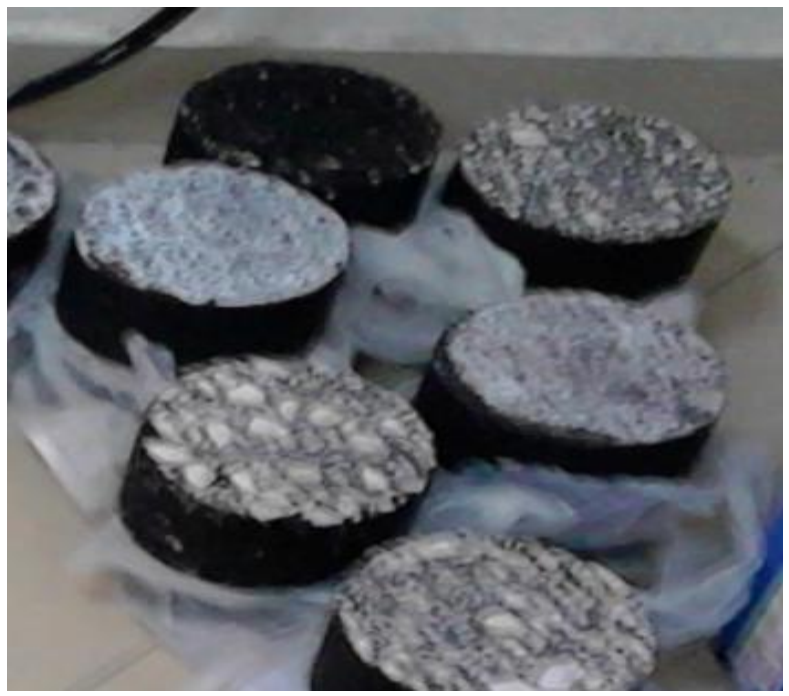

(d) APA SAMPLES

FIG. 3. SAMPLE PREPARATION FOR CWTT AND APA

Mehran University Research Journal of Engineering \& Technology, Volume 37, No. 3, July, 2018 [p-ISSN: 0254-7821, e-ISSN: 2413-7219] 
failure rut depth is considered to be $12.5 \mathrm{~mm}$ in line with past literature. The test was conducted was accordance with EN 12697-22.The specimens were conditioned at the specified test temperature of 40 and $50^{\circ} \mathrm{C}$ for a minimum period of 2 hours prior to testing. The specimen temperature was monitored by placing a dummy sample in the temperature controlled cabin of wheel tracking machine. Once required temperature was achieved, the test was started through software installed in the attached computer. The rut depth was automatically monitored by the attached LVDT (Linear Variable Differential Transformer). The screen of attached computer shows the rut development curve in increments of $0.01 \mathrm{~mm}$. Test continued until terminal number of passes or failure rut depth, whichever was earlier.

The APA test is an empirical laboratory test that is assumed to simulate actual field performance of asphalt concrete trafficked by heavy vehicles. The APA test does not directly measure mixture material properties; therefore, it can be primarily used to rank relative rut resistance of different mixtures. In APA tests, samples were conditioned for a period of 12 hours prior to testing. The air voids were kept in the range of $6 \pm 0.5 \%$ to simulate actual conditions of road pavements. The terminal number of cycles was limited to 8000 with loading magnitude of 100 $\mathrm{lbs}$ and hose pressure of $100 \mathrm{psi}$. The loading frequency was $59 \mathrm{~Hz}$, while the failure rut depth was considered to be $5 \mathrm{~mm}$ in line with the previous published work [7]. The test was conducted in accordance with AASHTO TP 63. Before APA test, load and height calibration of the equipment was verified. Preheated molded specimens were inserted in the APA machine as shown in Fig. 4. The chamber doors were closed for minimum of 10 minutes after placing the specimens in order to stabilize the temperature prior to testing. Twenty-five cycles were applied to seat the specimens before recording the initial reading. At the completion of maximum cycles, APA test was terminated, and the wheels were automatically retracted.
In CWTT and APA test, samples were tested in the confined state. The wheel used in CWTT is composed of solid rubber while in APA test pressurized rubber hose is used to transfer load to the specimen, therefore APA better simulates load transfer mechanism of an actual vehicle wheel.

\section{RESULTS AND DISCUSSION}

\subsection{Mixtures Evaluation}

The rutting susceptibility of selected asphalt mixtures has been evaluated on basis of terminal rut depth. Ranking of thirty wearing course mixtures using CWT test has been shown in Fig. 5. All the wearing course mixtures were tested at temperature conditions of 40 and $50^{\circ} \mathrm{C}$. The temperature conditions have been selected on the basis of high temperature range experienced by on-field asphalt mixtures in major hot climatic areas of the country.

Fig. 5 shows the terminal rut depth of selected wearing course mixtures at 10,000 passes of CWT. Bar charts have been plotted to rank various asphalt mixtures. The length of bars indicates the terminal rut depth on primary vertical axis, while the mixtures have been shown on horizontal axis. Bitumen penetration has been plotted as diamond shaped bullets on secondary vertical axis. It has been observed that none of the mixtures reached failure rut depth of $12.5 \mathrm{~mm}$ before the terminal number of 10,000 wheel load passes. Mixture ranking is observed to be identical for both temperature conditions of 40 and $50^{\circ} \mathrm{C}$. Mixtures with Ubhan shah aggregates and NRL 60/70 penetration grade bitumen (i.e. M1, M2, M3, M4, and M5) showed least resistance to rutting while, mixtures with Margallah aggregates and NRL 40/50 penetration grade bitumen (i.e. M16, M17, M18, M19, and M20) have relatively better resistance to rutting among the selected mixtures. Sargodha aggregate mixtures have performed better than Ubhan Shah aggregate mixtures, but are more prone to rutting as compared to Margallah aggregate mixtures. The

Mehran University Research Journal of Engineering \& Technology, Volume 37, No. 3, July, 2018 [p-ISSN: 0254-7821, e-ISSN: 2413-7219] 
influence of particle shape on mixture stability and rutting susceptibility can be found in past researches $[28,29]$. For Ubhan Shah aggregates, the higher FI (Flakiness Index) as compared to minimum limit of $10 \%$ as mentioned in NHA specifications for wearing course mixtures, might be reason of more rut susceptible mixtures [27]. The rutting resistance has been increased by $56,64,65,69$, and 56\% for M16, M17, M18, M19 and M20 mixtures with the use of Margallah aggregate source as compared to mixtures M6, M7, M8, M9 and M10

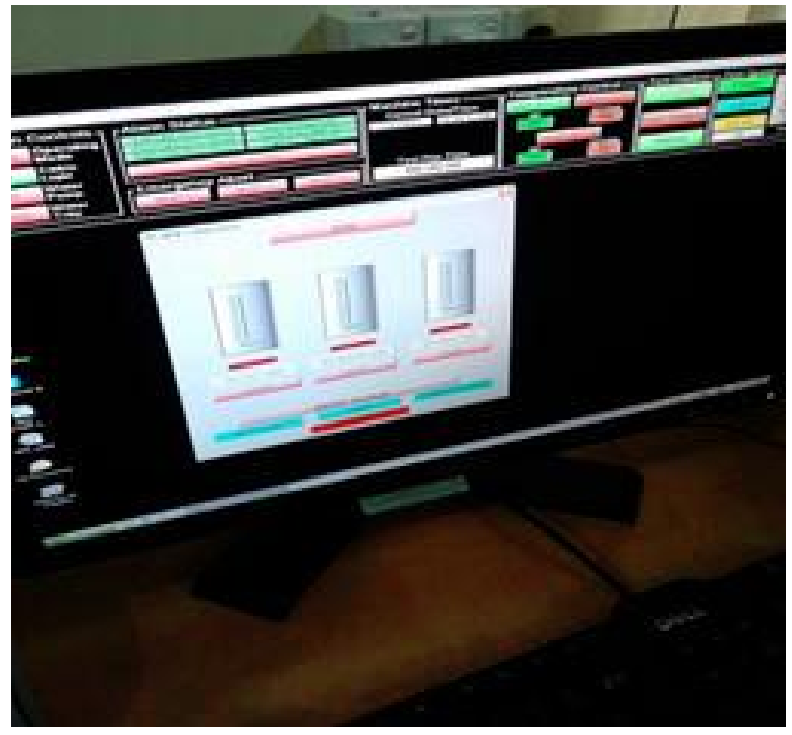

(a) HEIGHT CALIBRATION

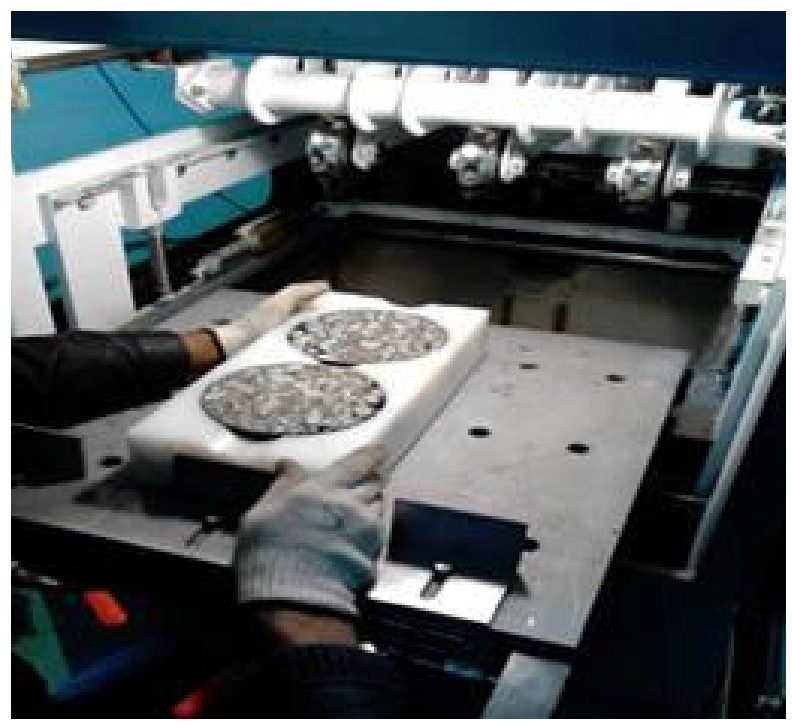

(c) INSERTING MOLDED SAMPLE prepared using Ubhan Shah aggregates along with NRL $40 / 50$ penetration grade bitumen at a specific temperature of $50^{\circ} \mathrm{C}$. The standard error bars shown in Fig. 5 indicates that the variation among replicates is greater for higher test temperature of $50^{\circ} \mathrm{C}$ as compared to $40^{\circ} \mathrm{C}$.

The results of APA test have been presented in Fig. 6 for selected wearing course mixtures. The mixture ranking with respect to total rut depth has been observed to be similar to that of the trends observed in CWT test.

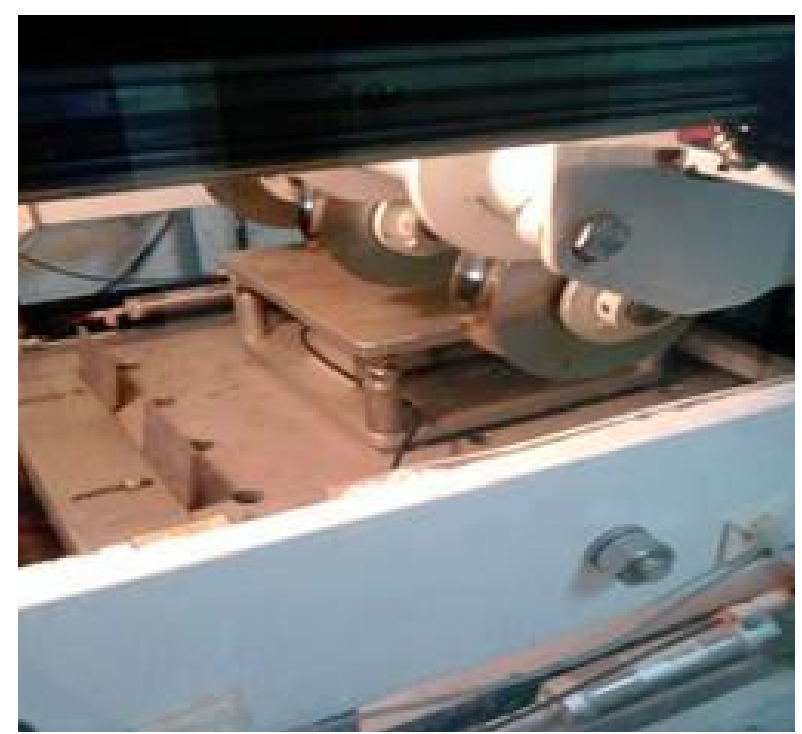

(b) LOAD CALIBRATION

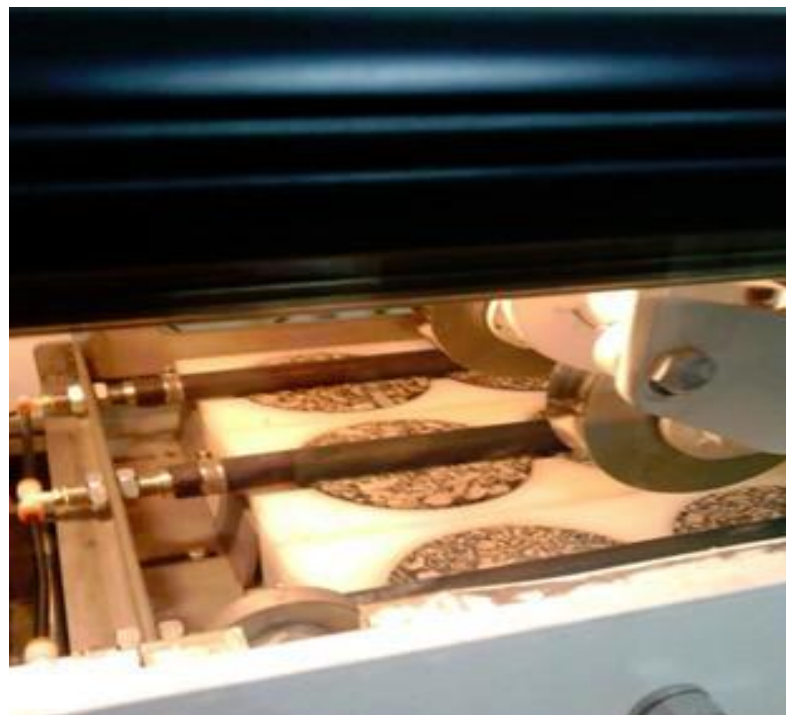

(d) SAMPLE READY TO BE TESTED

FIG. 4. ASPHALT PAVEMENT ANALYZER TEST IN PROGRESS

Mehran University Research Journal of Engineering \& Technology, Volume 37, No. 3, July, 2018 [p-ISSN: 0254-7821, e-ISSN: 2413-7219] 
From Fig. 6, it can be observed that none of the mixture reached the failure rut depth of $5 \mathrm{~mm}$ before the terminal number of 8000 cycles. The standard error bars show a least variation among values in case of mixtures with NRL 40/50 penetration grade bitumen. Among wearing course mixtures, M5 showed maximum rut depth while, M16 has least rut depth. It has been inferred that the aggregate source, bitumen source and penetration grade has less dominant effect on rutting performance for coarse graded mixture of NHA-A.

\subsection{Marginal Mean Plots}

Based on the test data of the whole scheme, different variables are categorized as dependent and independent variables. Influence of independent variables of temperature, aggregate source, and binder type, on dependent variables of rut depth rate has been determined by marginal mean plots shown in Fig. 7. Aggregate source has been designated by FI of aggregates), while, bitumen type by penetration value. FI is 12,8 , and 4.75 for Ubhan
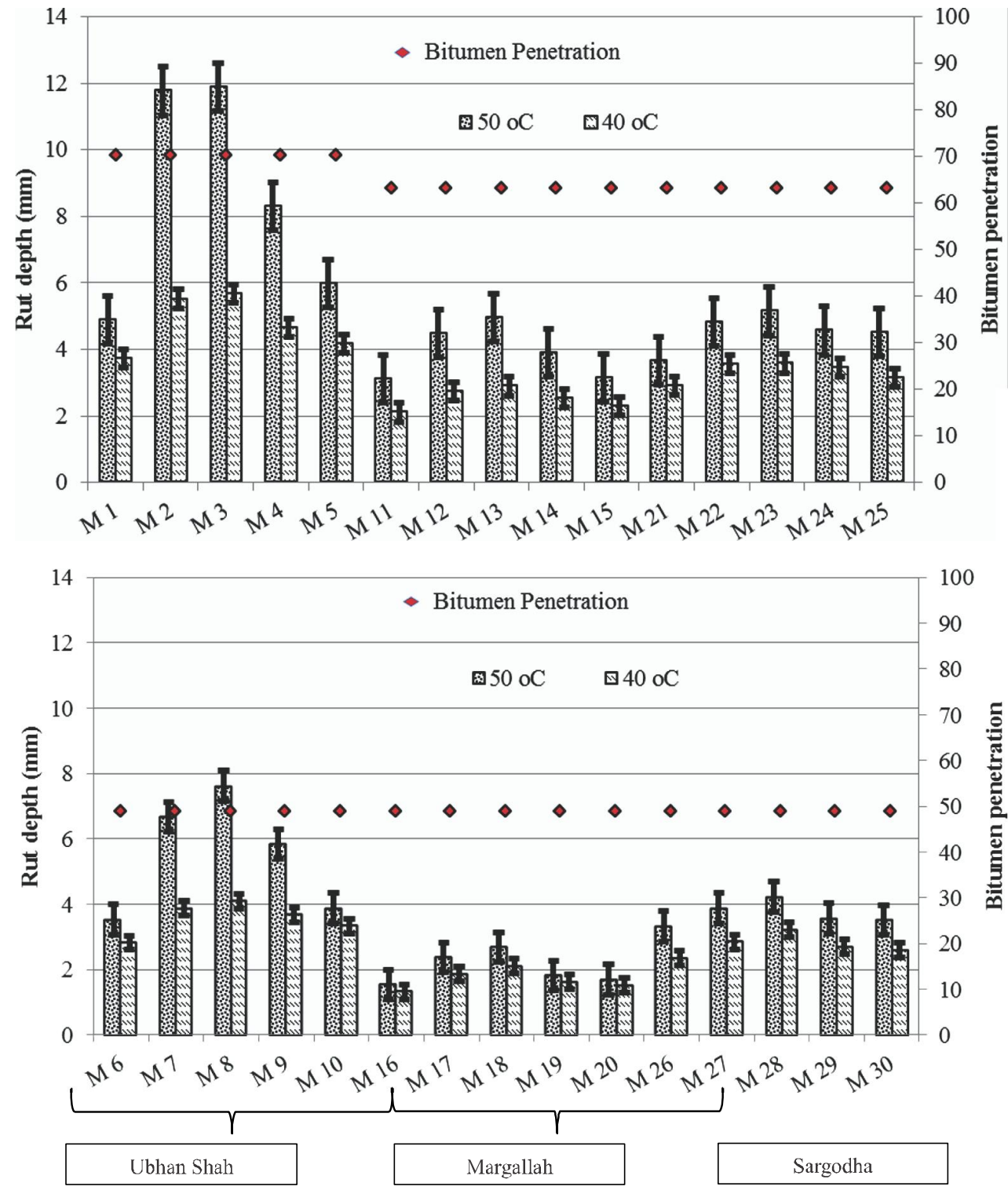

FIG. 5. TEST RESULTS FOR COOPER WHEEL TRACKING TEST

Mehran University Research Journal of Engineering \& Technology, Volume 37, No. 3, July, 2018 [p-ISSN: 0254-7821, e-ISSN: 2413-7219] 
Shah, Sargodha and Margallah aggregates respectively. Penetration value of 40/50,60/70 NRL and 60/70 ARL was 49, 63 and 70 respectively. From Fig. 7, a general trend can be observed in both rutting performance tests, i.e. the Margallah aggregate quarry has performed better as compared to Sargodha and Ubhan Shah aggregate quarry. Moreover, rutting susceptibility was observed to be increased with increasing binder penetration grade and increasing temperature. The effect of aggregate source, bitumen type and temperature has been observed to be more pronounced in CWTT as compared to APA, as indicated by greater line slopes in Fig. 7.

\subsection{Prediction Model Development}

Prediction models are the performance equations used to predict pavement life and considered to be a critical empirical component in MEdesign. An important consideration in ME design is the accuracy of load response model that predicts pavement response under wheel loads. These models are typically derived from statistical correlations between pavement response and laboratory performance of test specimens. Hence, the validity of response prediction models is an important prerequisite for efficient design and reliable evaluation of pavement condition.

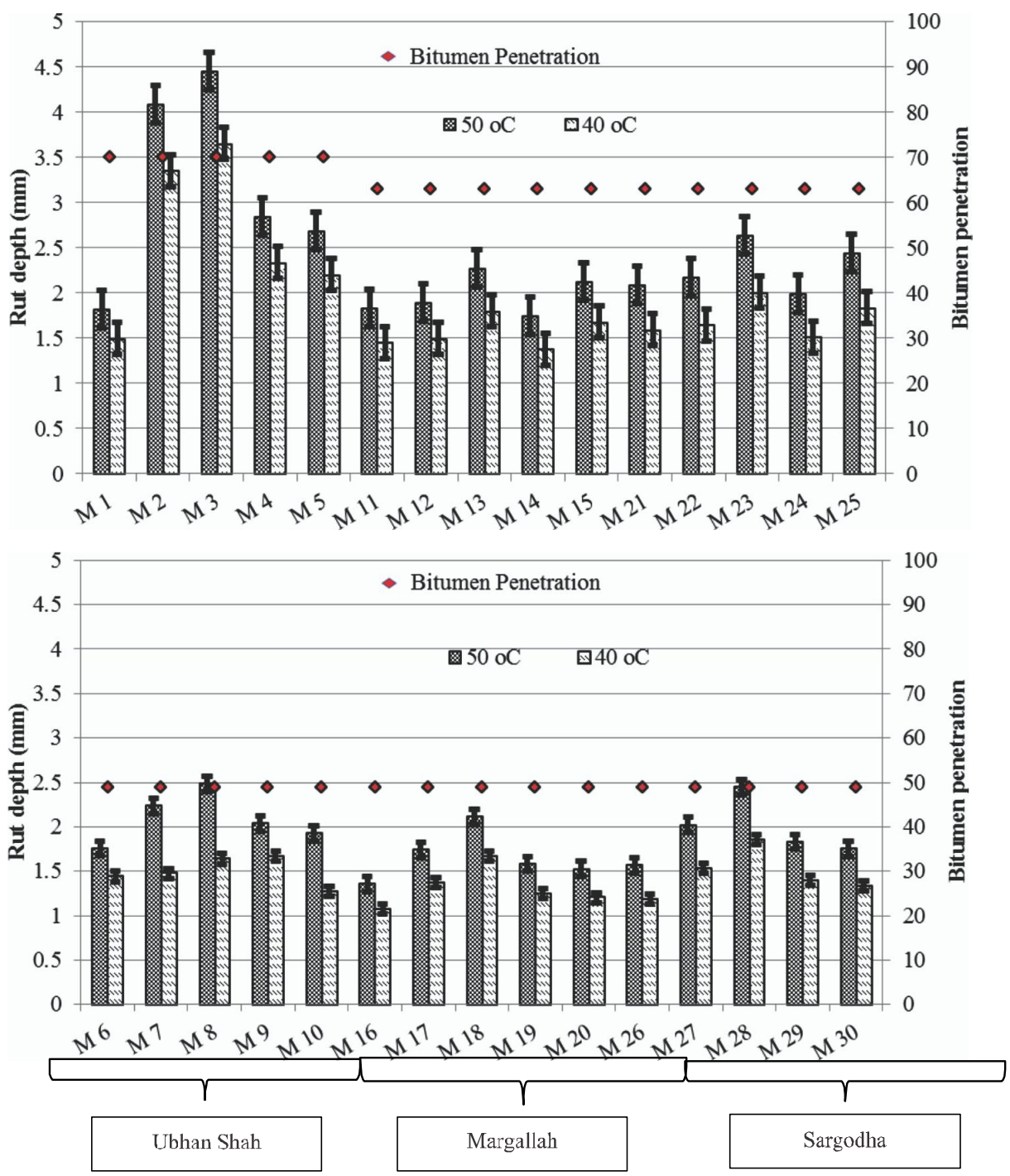

FIG. 6. TEST RESULTS FOR ASPHALT PAVEMENT ANALYZER TEST

Mehran University Research Journal of Engineering \& Technology, Volume 37, No. 3, July, 2018 [p-ISSN: 0254-7821, e-ISSN: 2413-7219] 


\subsubsection{Rutting Prediction Model Based on CWTT and APA Data}

It is well established fact that rutting of asphalt mixtures is affected by individual material properties, environmental, and traffic loading conditions. However, the simultaneous effect of all these parameters has not been previously modeled for prevailing environmental conditions and indigenous materials being used in road pavements in the country. The aggregates shape characteristics greatly influence the re-orientation of particles on application of load. Therefore, FI of aggregates has been included in the model. Bitumen acts as the visco-elastic binding material at varying temperature and loading frequency, and has a significant impact on mixtures rutting performance. Bitumen penetration indicates the relative stiffness of binder. Bitumen penetration grade test is one of mandatory tests included in the requirements of bitumen quality control

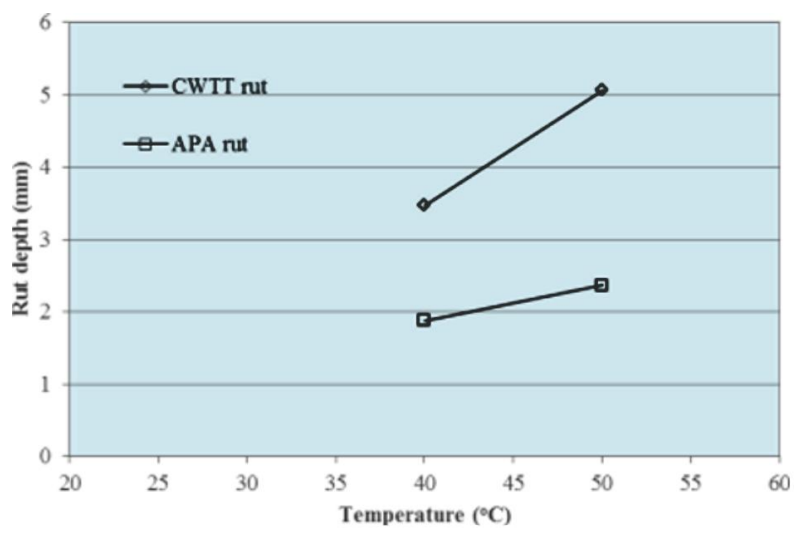

specifications. Therefore, it has been included in the model. Temperature variable most significantly affects the response of asphalt mixtures to rutting distress. Therefore, temperature variable has also been included in the model as a prime environmental factor. A loading related variable must be included finally. Loading stress is constant as per test standard procedure. Number of loading passes/cycles has been included in the model as a load related factor. Rutting values with each loading pass/cycle has been included for prediction model development in case of CWTT and APA respectively. Certain mixture preparation and compaction related variables such as VMA(Voids in Mineral Aggregates), VFA (Voids Filled with Asphalt), and OBC etc. are not included in the model because all these mixture properties were initially optimized using Marshall mixture design procedure. Furthermore, air voids are kept consistent in the range of $6 \pm 0.5 \%$, which simulates the on-field compaction.

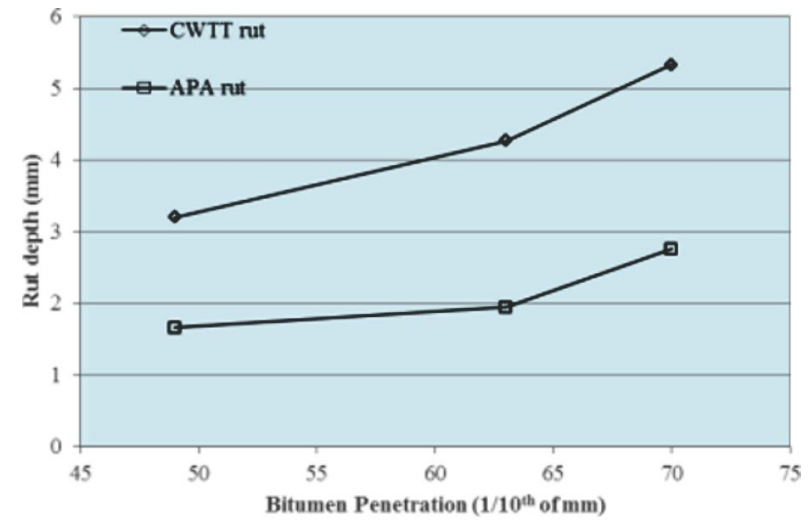

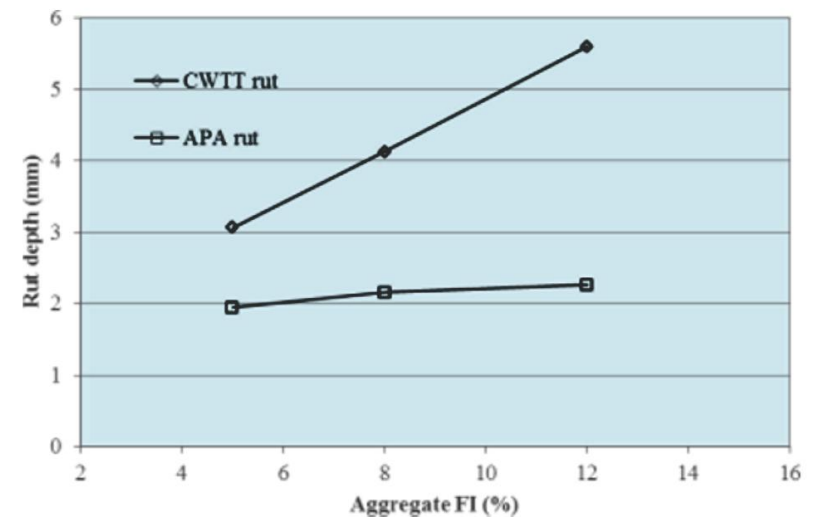

FIG. 7. MARGINAL MEAN PLOTS FOR RUT DEPTH IN CWTT AND APA TEST

Mehran University Research Journal of Engineering \& Technology, Volume 37, No. 3, July, 2018 [p-ISSN: 0254-7821, e-ISSN: 2413-7219] 
Non-linear multiple regression modeling technique in SPSS statistical analysis software was used to develop a rutting prediction model based on the results of confined simulative tests of CWT test and APA test on all the asphalt wearing course mixes. Rut depth in units of millimeter is considered as the dependent variable. The independent variables include temperature in ${ }^{\circ} \mathrm{C}$ denoted by ' $\mathrm{T}$ ', number of passes in case of CWTT or number of cycles in case of APA denoted by ' $N$ ', bitumen penetration value ' $\mathrm{P}$ ' measured to nearest $1 / 10^{\text {th }}$ of $\mathrm{mm}$, and Flakiness
Index of coarse aggregates 'FI' in percent. The general equation can be written as shown in Equation (5).

Rut Depth $=\mathrm{a} * \mathrm{~T}^{\mathrm{b}} * \mathrm{~N}^{\mathrm{c}} * \mathrm{P}^{\mathrm{d}} * \mathrm{FI}^{\mathrm{e}}$

Where a, b, c, d, and e are regression coefficients/ parameters

After several iterations performed to minimize total error sum of squares, the output of regression analysis for rutting data of CWTT and APA has been shown below in Table 4.

TABLE 4. PARAMETER ESTIMATES OF NON-LINEAR REGRESSION MODEL (CWTT AND APA)

\begin{tabular}{|c|c|c|c|c|c|c|c|}
\hline \multirow{2}{*}{ CWTT } & \multirow{2}{*}{ APA } & \multicolumn{3}{|c|}{ CWTT } & \multicolumn{3}{|c|}{ APA } \\
\hline & & Estimate & t-stat* & Standard Error & Estimate & t-stat* & Standard Error \\
\hline $\bar{a}$ & - & $3.55 \mathrm{E}-06$ & - & 0.000 & 0.000 & - & 0.000 \\
\hline $\mathrm{b}$ & 12.71 & 1.269 & 40.94 & 0.031 & 1.048 & 20.96 & 0.05 \\
\hline $\mathrm{c}$ & 1.96 & 0.483 & 69.00 & 0.007 & 0.353 & 32.09 & 0.011 \\
\hline $\mathrm{d}$ & 4.30 & 0.798 & 38.00 & 0.021 & 0.396 & 9.66 & 0.041 \\
\hline $\mathrm{e}$ & 4.30 & 0.528 & 52.80 & 0.01 & 0.165 & 9.71 & 0.017 \\
\hline \multicolumn{8}{|c|}{ NHA-B } \\
\hline $\mathrm{a}$ & - & $1.23 \mathrm{E}-09$ & - & 0.000 & $1.91 \mathrm{E}-06$ & - & 0.000 \\
\hline $\mathrm{b}$ & 12.71 & 2.503 & 65.87 & 0.038 & 1.136 & 39.17 & 0.029 \\
\hline $\mathrm{c}$ & 1.96 & 0.611 & 76.38 & 0.008 & 0.342 & 68.40 & 0.005 \\
\hline $\mathrm{d}$ & 4.30 & 1.288 & 56.00 & 0.023 & 1.336 & 63.62 & 0.021 \\
\hline $\mathrm{e}$ & 4.30 & 0.771 & 64.25 & 0.012 & 0.526 & 52.60 & 0.010 \\
\hline \multicolumn{8}{|c|}{ SP-A } \\
\hline $\bar{a}$ & - & $2.37 \mathrm{E}-09$ & - & 0.000 & $3.69 \mathrm{E}-06$ & - & 0.000 \\
\hline $\mathrm{b}$ & 12.71 & 2.362 & 71.58 & 0.033 & 1.139 & 47.46 & 0.024 \\
\hline $\mathrm{c}$ & 1.96 & 0.599 & 85.57 & 0.007 & 0.323 & 80.75 & 0.004 \\
\hline $\mathrm{d}$ & 4.30 & 1.33 & 63.33 & 0.021 & 1.328 & 78.11 & 0.017 \\
\hline $\mathrm{e}$ & 4.30 & 0.717 & 65.18 & 0.011 & 0.375 & 46.88 & 0.008 \\
\hline \multicolumn{8}{|c|}{ SP-B } \\
\hline $\mathrm{a}$ & - & $4.68 \mathrm{E}-08$ & - & 0.000 & $4.89 \mathrm{E}-05$ & - & 0.000 \\
\hline $\mathrm{b}$ & 12.71 & 1.72 & 37.39 & 0.046 & 1.024 & 33.03 & 0.031 \\
\hline $\mathrm{c}$ & 1.96 & 0.518 & 64.75 & 0.008 & 0.312 & 52.00 & 0.006 \\
\hline $\mathrm{d}$ & 4.30 & 1.356 & 50.22 & 0.027 & 0.735 & 35.00 & 0.021 \\
\hline $\mathrm{e}$ & 4.30 & 0.65 & 50.00 & 0.013 & 0.405 & 40.50 & 0.010 \\
\hline \multicolumn{8}{|c|}{ MS-II } \\
\hline $\mathrm{a}$ & - & $2.42 \mathrm{E}-07$ & - & 0.000 & $1.24 \mathrm{E}-05$ & - & 0.000 \\
\hline $\mathrm{b}$ & 12.71 & 1.649 & 35.09 & 0.047 & 1.181 & 56.24 & 0.021 \\
\hline $\mathrm{c}$ & 1.96 & 0.523 & 52.30 & 0.010 & 0.344 & 86.00 & 0.004 \\
\hline $\mathrm{d}$ & 4.30 & 0.997 & 32.16 & 0.031 & 1.020 & 68.00 & 0.015 \\
\hline $\mathrm{e}$ & 4.30 & 0.633 & 42.20 & 0.015 & 0.095 & 15.83 & 0.006 \\
\hline
\end{tabular}


The 'Standard Error' column of Table 4 shows the precision with which the value of parameter has been estimated. T-statistic or simply t-test is a useful statistical tool to infer the significance of various statistical coefficients/ parameters. It is computed by dividing the estimated value of parameter by its standard error. The computed t-stat has been compared with t-critical value, determined by respective degrees of freedom and confidence level. The confidence level of $95 \%$ has been selected. Degree of freedom has been calculated by number of terms ' $\mathrm{N}$ ' minus one. If the computed t-stat values are greater than t-critical, the respective coefficients/ parameters and their associated variables are significant in the model. The values of these statistical terms have been shown in Table 4 for various gradations tested in CWTT and APA test. The analyzed parameters are found to be significant for all the wearing course gradations and both rutting performance tests of CWTT and APA.

\subsubsection{Validation of Model}

The developed prediction model has been validated by plotting the measured and predicted rutting development curves simultaneously for same asphalt mixtures, and comparing those plots as shown in Figs. $8-9$. The rutting development curves with rut depth as ordinate and number of passes/ cycles on abscissa of twelve representative asphalt mixtures at the high temperature of $50^{\circ} \mathrm{C}$ have been shown in Figs. 8-9 for CWTT and APA, respectively. It is important to note that similar plots could be shown for all the thirty selected asphalt mixtures; however, twelve mixtures with variable aggregate source, bitumen type, and aggregate gradations have been shown in Figs. 8-9 as a representative sample. These representative mixtures include six mixtures with relatively coarser gradation of NHA-A and six mixtures with relatively finer gradation of SP-A. Six mixtures further consist of two mixtures with each of three aggregate sources of Ubhan Shah, Margallah and Sargodha combined either with $60 / 70$ or $40 / 50$ penetration grade bitumen. It has been observed that the predicted and measured values lie close to each other. In case of CWTT, rutting curve of mixture M1 has been predicted with maximum accuracy; while, the estimated rut depth is being over-estimated for most rut resistance mixture M16. It has been further detected that for SP-A graded mixtures M3 and M8, the initial and final rut depth of actual and predicted curves is very close to each other, but the curves minutely deviate apart at intermediate values. This behavior could be due to high consistent rutting rate of the laboratory observed rutting curves. In case of APA, initial rutting is highest for mixture M1, but gradually it stabilized with the increase in loading cycles.

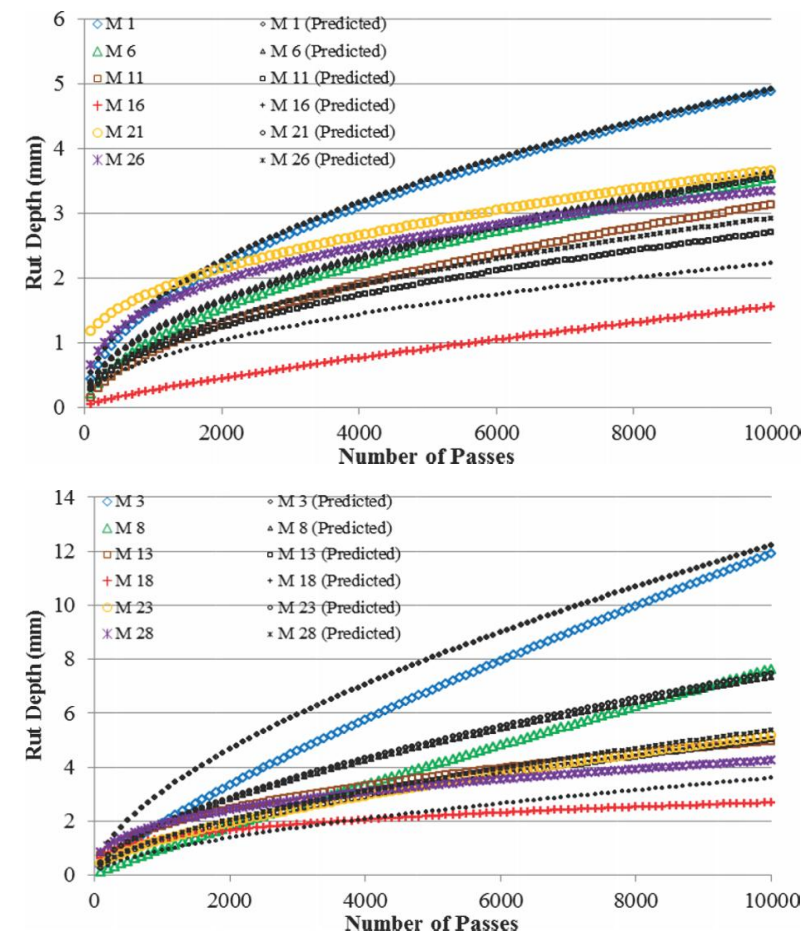

FIG. 8. PREDICTION MODEL VALIDATION USING RUTTING DEVELOPMENT CURVES OF REPRESENTATIVE MIXTURES FOR CWTT $\left(A T 50^{\circ} \mathrm{C}\right)$ 
Using the estimated values of regression coefficients/ parameters, $\mathrm{x}-\mathrm{y}$ scatterplot has been drawn between measured and predicted values, $\mathrm{R}^{2}$ of linear trend line between measured and predicted rut depth has been found to be 0.92 and 0.95 for CWTT and APA data, respectively as shown in Figs. 10-11. It has been observed that same non-linear regression model predicts APA rut data more accurately as compared to CWTT rut data.

\subsubsection{Sensitivity of Rutting Prediction Model}

Sensitivity of different independent variables in the model can be judged by the value of regression parameter associated as a power of each variable. In the rutting prediction models discussed above, it has been observed that temperature variable represented by $T$ has the highest value of regression parameter; which indicates that $\mathrm{T}$ has maximum influence on the model. Bitumen penetration variable represented by $\mathrm{P}$ is the second most influential variable in case of both CWTT and APA test prediction models.

\subsection{Comparison and Correlation of Rutting Performance Tests}

\subsubsection{Comparison of CWTT and APA}

In order to compare different performance tests, time in seconds required to produce a rut depth of $1 \mathrm{~mm}$ for all wearing course mixtures tested at a constant temperature of $50^{\circ} \mathrm{C}$ was chosen [21]. The duration of a single cycle was 2.26 and $1 \mathrm{sec}$ for CWTT and APA, respectively.

It can be observed from Fig. 12 that the time required to produce a rut depth of $1 \mathrm{~mm}$ is maximum for APA test. This is due to the fact that APA specimens were compacted using Gyratory compactor; which results in a better control on volumetrics as compared to CWTT slabs compacted by Cooper roller compactor. The combined effect of proper compaction and confinement might be the reason of better performance of mix for APA test.

\subsubsection{Correlation between CWTT and APA Rut Depth}

A correlation has been developed between rut depth obtained from Cooper wheel tracking test and asphalt pavement analyzer test, shown in Fig. 13. The proposed relationship (Equation (6)) can be used to predict APA rut values using CWTT rut values.

$\operatorname{Rut}_{\mathrm{APA}}=0.4754 * \operatorname{Rut}_{\mathrm{CWTT}}{ }^{2}+0.0345 * \operatorname{Rut}_{\mathrm{CWTT}}+1.8231$
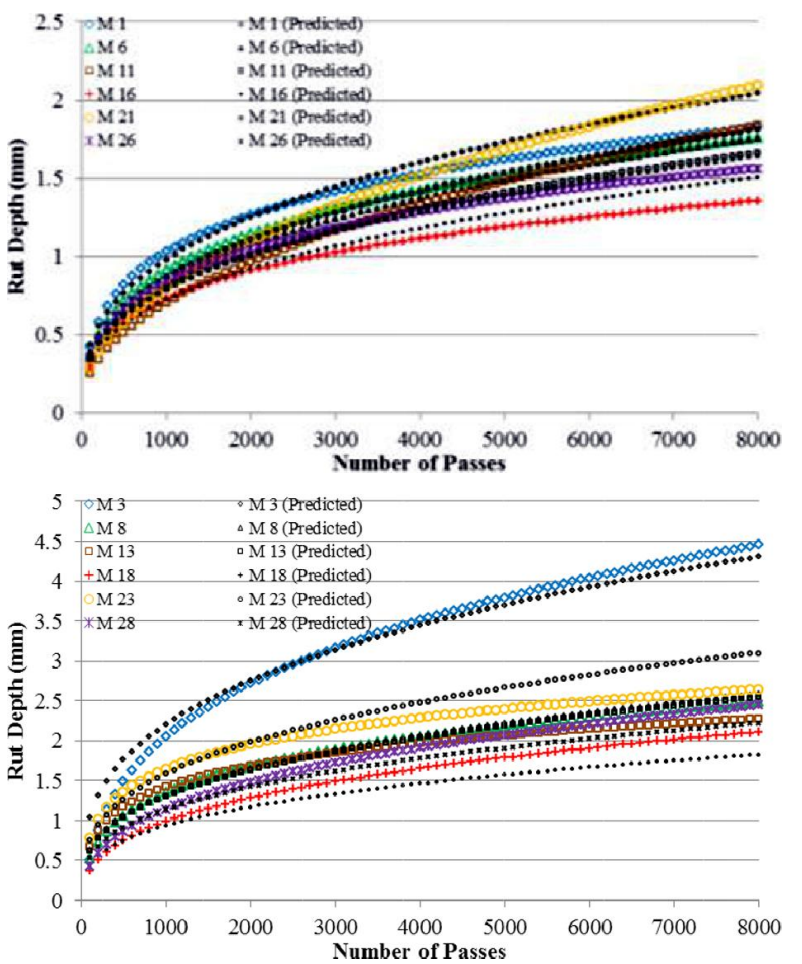

FIG. 9. PREDICTION MODEL VALIDATION USING RUTTING DEVELOPMENT CURVES OF REPRESENTATIVE MIXTURES FOR APA $\left(A T 50^{\circ} \mathrm{C}\right)$

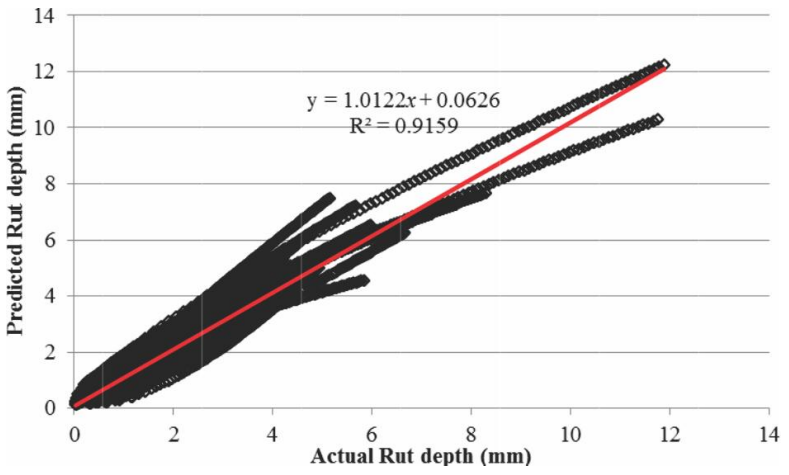

FIG. 10. PREDICTED VS. ACTUAL RUT DEPTH PLOT FOR CWTT

Mehran University Research Journal of Engineering \& Technology, Volume 37, No. 3, July, 2018 [p-ISSN: 0254-7821, e-ISSN: 2413-7219] 
A quadratic function correlates the CWTT rut depth with APA rut depth with significant accuracy as indicated in Fig. 13. It elaborates the fact that CWTT rutting value is generally greater than APA rutting values. This observation is logical as loading frequency is less in case CWTT than APA, slower the frequency of load greater is the permanent deformation of asphalt mix.

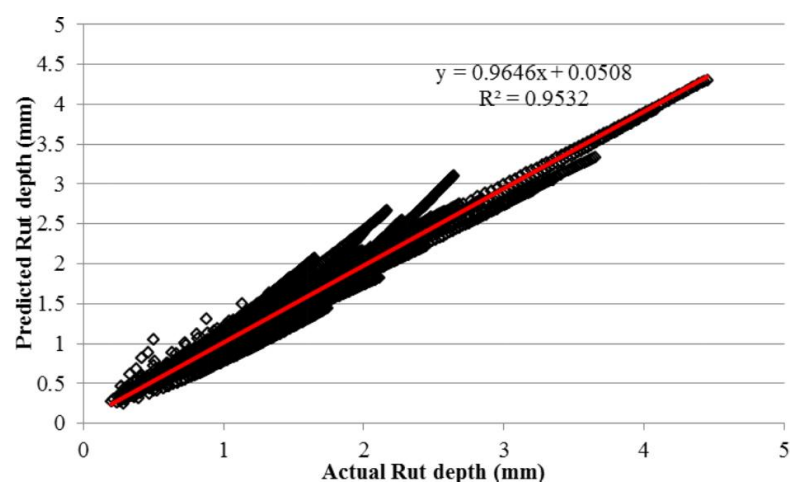

FIG. 11. PREDICTED VS. ACTUAL RUT DEPTH PLOT FOR $A P A$

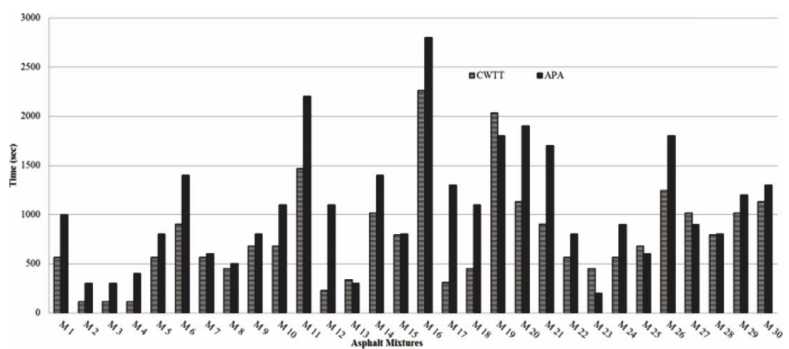

FIG. 12. PLOT OF TIME (SECONDS) TO ACHIEVE RUT OF I $M M$ FOR CWTT AND APA AT $50^{\circ} \mathrm{C}$

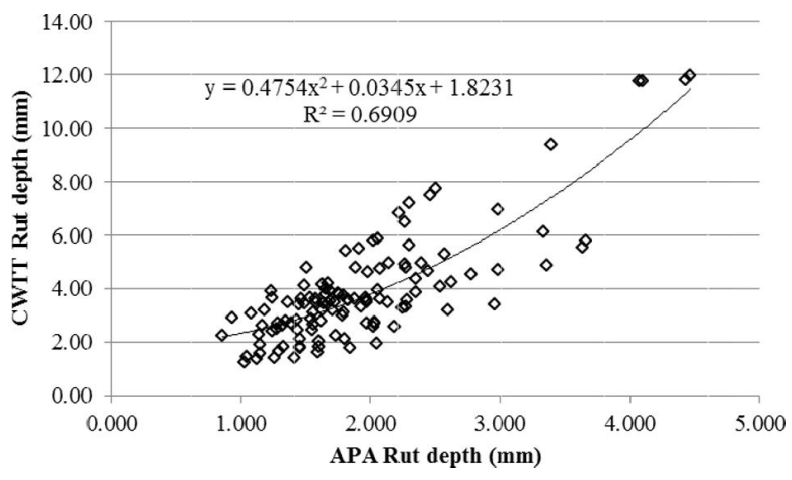

FIG. 13. CORRELATION PLOT BETWEEN CWTT RUT DEPTH AND APA RUT DEPTH
The study initially focused on relative evaluation and ranking of asphalt mixtures with indigenous constituent materials. The local gradations specified by NHA Pakistan along with globally specified gradations of Superpave and Asphalt Institute, have been incorporated in the study. This study could serve as a useful tool to predict the suitability of various combinations of materials and gradations for different regions of the country. The prediction model developed in this study highlighted significant variables for prediction of laboratory rutting performance of asphalt mixtures. This model could be extended to other aggregate and bitumen sources in Pakistan. The incorporation of wide range of mixtures would be beneficial for national and provincial highway agencies to develop a generalized visco-elastic temperature dependent model. The correlation between CWTT and APA recommend that instead of dealing with the costly and complicated rut simulation technique of APA; the industry can utilize CWTT as an alternative tool. In other words, this relationship enables the pavement industry to compare mix performances with international projects at a fairly easy and economical cost; as APA is being used as an effective rutting simulation tool in majority of the countries, worldwide. The applicability of this study in introduction of performance based quality control procedures for the pavement industry has been highlighted in above discussion. The practitioners and material engineers are interested in utilization of laboratory performance for simulation of on-field performance of asphalt mixtures. Each cycle of the APA wheel is found to be equivalent to about 130 rutting ESALs. The 8000 cycles/strokes represent 1,040,000 ESALs [30]. The similar criterion needs to be developed for CWTT in order to relate it with field performance. 


\section{CONCLUSIONS}

(i) It has been observed that mixture ranking is same for both temperature conditions of 40 and $50^{\circ} \mathrm{C}$. It has been further observed that variability among the rut depths of different mixtures reduces at lower temperature of $40^{\circ} \mathrm{C}$. Additionally, trend of rutting susceptibility was same for mixtures with Ubhan Shah, Margallah and Sargodha aggregates; however, the rut depth values for Ubhan Shah aggregates are on higher side. For Ubhan Shah aggregates, the higher FI higher than maximum specified requirement of $10 \%$ might be reason of more rut susceptible mixtures. For same aggregate source, mixtures having low penetration grade bitumen have performed better against rutting.

(ii)

It has been observed that non-linear regression technique can be used to develop a laboratory rutting prediction model. It was inferred that the temperature, number of passes in case of CWTT or number of cycles in case of APA, bitumen penetration value, and flakiness index of coarse aggregates; are significant variables included in the developed rutting prediction models. The effectiveness of model is quantified by $\mathrm{R}^{2}$ of linear trend line between measured and predicted rut depth, which has been found to be 0.92 and 0.95 for CWTT and APA data, respectively. It had been further observed that regression parameter associated with temperature variable has highest value; which indicates maximum influence of temperature variable on the developed prediction model for both CWTT and APA test results.

(iii)

\section{ACKNOWLEDGEMENTS}

The authors acknowledge Highway Research and Training Center, working under the umbrella of National Highway Authority, Pakistan, for financial assistance of the research project. The authors assure and confirm that there are no personal or institutional conflicts of interest with this article.

\section{REFERENCES}

[1] Parker, F., and Brown, E.R., "A Study of Rutting of Albama Asphalt Pavements", Final Report Project Number ST 2019-9 Auburn University Highway Research Center, Auburn University, Alabama Sponsored by The State of Alabama Highway Department Montgomery, Alabama, United States of America, 1990.

[2] Hafeez, I., Ozer, H., and Al-Qadi, I., "Performance Characterization of Hot In-Place Recycled Asphalt Mixtures", Journal of Transportation Engineering, Volume 140, No. 8, pp. 4014029, [DIO:10.1061/ (ASCE)TE.1943-5436.0000679], USA, 2014.

[3] Doyle, J.D., and Howard, I.L., "Rutting and Moisture Damage Resistance of High Reclaimed Asphalt Pavement Warm Mixed Asphalt: Loaded Wheel Tracking vs. Conventional Methods", Road Materials and Pavement Design, Volume 14, No. S2, pp. 148-172, [DOI:10.1080/14680629.2013.812841], UK, 2013.

[4] Al-Hadidy, A., and Yi-qiu, T., "Effect of StyreneButadiene-Styrene on the Properties of Asphalt and StoneMatrix-Asphalt Mixture", Journal of Materials in Civil Engineering, Volume 23, No. 4, pp. 504-510, [DOI:10.1061/(ASCE)MT.1943-5533.0000185], USA, 2011.

[5] Chandra, S., and Choudhary, R., "Performance Characteristics of Bituminous Concrete with Industrial Wastes as Filler", Journal of Materials in Civil Engineering, Volume 25, No. 11, pp. 1666-1673, [DOI:10.1061/(ASCE)MT.1943-5533.0000730], USA, 2013.

[6] Martin, A., and Park, D., "Use of the Asphalt Pavement Analyzer and Repeated Simple Shear Test at Constant Height to Augment Superpave Volumetric Mix Design", Journal of Transportation Engineering, Volume 129, No. 5, pp. 522-530, [DOI:10.1061/(ASCE)0733-947X], USA, 2003

[7] Choubane, B., Page, G.C., and Musselman, J.A., "Suitability of Asphalt Pavement Analyzer for Predicting Pavement Rutting", Transportation Research Record, Volume 1723, pp. 107-115, [DOI:10.3141/1723-14], USA, 2000. 
[8] Rushing, J.F., Little, D.N., and Garg, N., "Using the Asphalt Pavement Analyzer to Assess Rutting Susceptibility of HMA Designed for High Tire Pressure Aircraft", $91^{\text {st }}$ Annual Meeting of Transportation Research Board, Washington DC, USA, 2012.

Kim, Y.K., Park, H.M., Aragao, F.T.S., and Lutif, J.E.F., "Effects of Aggregate Structure on Hot-Mix Asphalt Rutting Performance in Low Traffic Volume Local Pavements", Construction and Building Materials, Volume 23, pp. 2177-2182, [DOI:10.1016/ j.conbuildmat.2008.12.007], USA, 2009.

[10] Yeo, Y.S., Jitsangiam, P., and Nikraz, H., "Erodability of Stabilized Pavements using the Wheel Tracking Test", International Conference on Advances in Geotechnical Engineering, [ISBN: 978-0-646-55142-5], Perth, Australia, November 7-9, 2011.

[11] Hafeez, I., Kamal, M.A., and Mahir, M., "Characterization of Hot Mix Asphalt using the Dynamic Modulus and Wheel Tracking Testing", Proceedings of Pakistan Academy of Sciences, Volume 49, No. 2, pp. 71-77, Pakistan, 2012.

[12] Apeagyei, A., "Rutting as a Function of Dynamic Modulus and Gradation", Journal of Materials in Civil Engineering, Volume 23, No. 9, pp. 1302-1310, [DOI:10.1061/(ASCE)MT.1943-5533.0000309], USA, 2011.

[13] Wang, H., Zhang, Q., and Tan, J., "Investigation of Layer Contributions to Asphalt Pavement Rutting", Journal of Materials in Civil Engineering, Volume 21, Special Issue: China: Innovative Use of Materials for Highway Construction, pp. 181-185, [DOI:10.1061/ (ASCE)0899-1561], USA, 2009.

[14] Ahmed, A.W., and Erlingsson, S., "Evaluation of a Permanent Deformation Model for Asphalt Concrete Mixtures using Extra-Large Wheel-Tracking and Heavy Vehicle Simulator Tests", Road Materials and Pavement Design, Volume 15, No. 4, pp. 1-18, [DOI:10.1080/ 14680629.2014.987311], UK, 2014.

[15] Tapkin, S., Cevik, A., and Usar, U., "Accumulated Strain Prediction of Polypropylene Modified Marshall Specimens in Repeated Creep Test using Artificial Neural Networks", Expert Systems and Applications, Volume 36, pp. 11186-11197, [DOI:10.1016/ j.eswa.2009.02.089], USA, 2009.

[16] Mirzahosseini, M., Najjar, Y.N., Alavi, A.H., and Gandomi, A.H., "ANN-Based Prediction Model for Rutting Propensity of Asphalt Mixtures", 92 ${ }^{\text {nd }}$ Annual Meeting of Transportation Research Board, Washington DC, USA, 2013.

[17] Archilla, A.R., and Madanat, S., "Development of a Pavement Rutting Model from Experimental Data", Journal of Transportation Engineering, Volume 126, No. 4, pp. 291-299, [DOI:10.1061/(ASCE)0733947X(2000], USA, 2000.
Archilla, A.R., "Use of Superpave Gyratory Compaction Data for Rutting Prediction", Journal of Transportation Engineering, Volume 132, No. 9, pp. 734-741, [DOI:10.1061/(ASCE)0733-947X], USA, 2006

[19] Hu, S., Zhou, F., and Scullion, T., "Development, Calibration, and Validation of a New M-E Rutting Model for HMA Overlay Design and Analysis", Journal of Materials in Civil Engineering, Volume 23, No. 2, pp. 89-99, [DOI:10.1061/(ASCE)MT.19435533.0000130], USA, 2011.

[20] Suh, Y.C., and Choand, N.M. "Development of a Rutting Performance Model for Asphalt Concrete Pavement Based on Test Road and Accelerated Pavement Test Data",KSCE Journal of Civil Engineering, Volume 18, No. 1, pp. 165-171, [DOI:10.1007/s12205-014-03945], Korea, 2014.

[21] Rushing, J., and Little, D., "Static Creep and Repeated Load as Rutting Performance Tests for Airport HMA Mix Design", Journal of Materials in Civil Engineering, Volume 26, No. 9, pp. 4014055, [DOI:10.1061/ (ASCE)MT.1943-5533.0000952], USA, 2014.

[22] Chen, X., Huang, B., and Xu, Z., "Comparison between Flat Rubber Wheeled Loaded Wheel Tester and Asphalt Pavement Analyzer", Road Materials and Pavement Design, Volume 8, No. 3, pp. 595-604, [DOI:10.1080/ 14680629.2007.9690090], UK, 2007.

[23] BS (British Standards), "Test Methods for Hot Mix Asphalt - Wheel Tracking Test”, EN BS 12697-22, Chiswick High Road, London, UK, 2002.

[24] AASHTO, "Determining the Rutting Susceptibility of Asphalt Paving Mixtures using Asphalt Pavement Analyzer Test”, TP 63-03, North Capitol Street, Washington, DC, USA, 2003.

[25] Asphalt Institute, "Asphalt Mix Design Methods", Manual Series No. 2, $7^{\text {th }}$ Edition, Kentucky, USA, 2014.

[26] Asphalt Institute, "Superpave TM Mix Design", Superpave Series SP-2, Lexington, Kentucky, USA, 1996.

[27] NHA, "General Specifications, Surface Courses", Item No. 305, Islamabad, Pakistan, 1998.

[28] Mahmud, M.Z.H., Yaacob, H., PutraJaya, R., and Abdul H.N., "Laboratory Investigation on the Effects of Flaky Aggregates on Dynamic Creep and Resilient Modulus of Asphalt Mixtures", Journal Teknologi, Volume 70, No. 4, pp. 107-110, Malaysia, 2014.

[29] PutraJaya, R., Abdul Hassan, N., Mahmud, M.Z.H., Aziz, M.A., Hamzah, M.O., and Chewan, C.N., "Effect of Aggregate Shape on the Properties of Asphaltic Concrete AC14", Journal Teknologi, Volume 71, No. 3, pp. 69-73, Malaysia, 2014.

[30] Skok, E., Johnson, E., and Turk, A., “Asphalt Pavement Analyzer (APA) Evaluation”,Final Report Project Number MN/RC 2003-2002, Department of Civil Engineering, University of Minnesota, USA, 2002. 